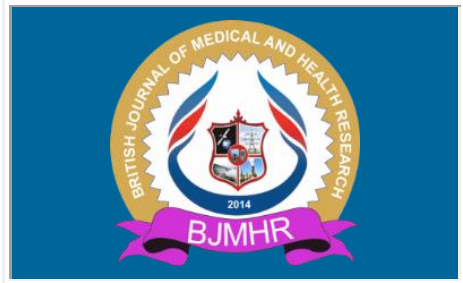

\title{
BJMHR
}

British Journal of Medical and Health Research

Journal home page: www.bjmhr.com

\section{The Effect of Cigarette Smoking on Semen Parameters Among Young Saudi Population}

\section{Thamer Mishal Alqurashi ${ }^{1}$, Raad Abdullah Aldahhas ${ }^{1}$, Samir Mohummed Abdul Fatah Atia ${ }^{2}$, Abdulhalim S. Serafi ${ }^{1}$, Syed Tabrez Ali ${ }^{*}$ \\ 1.Department of Physiology, Faculty of Medicine, Umm-Al-Qura University, Makkah, Saudi Arabia, \\ 2.Diagnostic laboratory, Health Department, Umm-Al-Qura Uuniversity, Makkah, Saudi} Arabia

\section{ABSTRACT}

Cigarette smoking is a lifestyle pattern. It is a major public health problem globally and is considered as one of the most important factor responsible for decline in semen quality and overall decline in male reproductive health. The objective of this study was to evaluate the effect of cigarette smoking on semen quality in young Saudi men living in Western region of Saudi Arabia (Makkah). In this free-living population study semen samples were collected from100 men each (mild, moderate and heavy cigarette smokers) ages between 20 and 35 years with a mean age of $26.42 \pm 10.69$ years by masturbation with the abstinence interval of sex or ejaculate of at least 72 hours, along with 100 age matched healthy nonsmokers who served as controls. Heavy cigarette smoker group was found to be associated with significantly low levels of sperm count, concentration, sperm motility, semen volume, and percentage of morphologically $(\mathrm{p}<0.0005)$. We hypothesized that heavy cigarette smoking seems to be associated with sub-fertility in these males by reducing semen quality in a dose-dependent manner.

Keywords: Cigarette smoking, seminal parameters, young Saudi men 


\section{INTRODUCTION}

Smoking is a major burden on the world's collective health system. Approximately 22.5 percent of adults in the world use tobacco products. Of which, $32 \%$ are men and $7 \%$ are women 1. In Saudi Arabia, prevalence of smoking is reported to be $2.4-52.3 \%$ (median: $17.5 \%$ ) (2). of this, it ranges from 12-29.8\% (median: $16.5 \%$ ) among school students and 2.4-37\% (median: $13.5 \%$ ) among university students ${ }^{2}$.

Smoking affects the human body systems by many ways. Tobacco contains over 4,000 toxins ${ }^{3}$. It exposes the body to free radicals leading to DNA damage and elevated oxidative stress ${ }^{4}$. Smoking can predispose to cancer (e.g. lung cancer) ${ }^{5}$, respiratory diseases (e.g. COPD) and can impair the immune function. Further, it has some musculoskeletal complications (e.g. osteoporotic fractures) ${ }^{6}$. It can also affect the cardiovascular system by inducing irreversible damage to myocardial and endothelial cells ${ }^{3}$. Regarding the nervous system, tobacco smoke increases the risk of stroke ${ }^{5}$, and can increase epinephrine and norepinephrine levels, In addition to its addictive nature ${ }^{7}$.

The evidence regarding smoking negative effects on semen parameter in the medical literature are conclusive. In a 2016 meta-analysis composed of twenty studies with 5865 participants showed an association between cigarette Smoking and reduced sperm count, motility, and abnormal morphology ${ }^{8}$. Moreover, another study which showed an abnormal chromatin condensation and a decrease in viability among smoker men compared to non-smoker ${ }^{9}$. In addition, Smokers had lower Testosterone and higher Prolactin levels with decreased semen volume compared to non-smoker ${ }^{10}$. A cross-sectional study showed an Inverse-dose dependent relationship between the number of cigarettes smoked daily and semen volume, sperm count and motility ${ }^{11}$.

The underlying mechanisms of smoking effect on semen parameter are not fully understood, but there are multiple known mechanisms which include sperm DNA fragmentation, caused by the increase in reactive oxygen species in the seminal fluid, and a decline in the sertoli and leydig cells secretions ${ }^{12}$. Smoking has also been proven to increase the risk of erectile dysfunction (ED) independent of comorbidities (Hypertension, diabetes, and obesity) and age, however early Smoking cessation might increase the chances of improving ED ${ }^{13}$.

The studies regarding the effect of smoking on semen parameter on a Saudi population are limited in number. AlEnezi et al, have studied samples of fertility clinic visitors in Riyadh, Saudi Arabia and concluded that smokers have a higher chance of having abnormalities in semen fluid and sperm function compared to non-smokers ${ }^{14}$. Another study had reached the same conclusion in a sample of infertile men ${ }^{15}$. 
The previous studies that targeted Saudi population are limited in number as stated above and more importantly, only focus on infertile people, and not the general population especially those who are younger in age.

The objective of this study is to evaluate the smoking effect on semen parameter in a Saudi population with age between $20-35$ years.

\section{MATERIALS AND METHOD}

\section{Study Design}

This cross-sectional study was carried in the Makkah Region of Saudi Arabia. The Umm Al Qura University, College of Medicine, Ethical and Protocol review committee reviewed and approved the study. Prior to the study all the subjects were provided with a written informed consent.

A total of 480 men in communities within the Makkah region, were spoken. Subjects visiting fertility clinic, with varicocele, history of testes injury, occupational exposure, subjects with a history of chronic urinary tract infection, subjects with disorders such as diabetes mellitus, hypertension and coronary heart diseases were excluded from the study. Finally 100 men each (mild, moderate and heavy smokers) ages of 20 and 35 years with a mean age of $26.42 \pm 10.69$ years along with 100 age matched healthy non smokers (control group) agreed to participant in the study.

Smokers were defined as subjects who have smoked cigarette (and are still smoking) continuously for at least 5 years. Smokers who smoked less than five $(<5)$ sticks of cigarette per day were classified as mild smokers, between 5 and 10 sticks of cigarette per day as moderate smokers and more than ten $(>10)$ sticks per day as heavy smokers.

\section{Sample Collection}

All the subjects were requested to collect the ejaculates by masturbation with the abstinence interval of sex or ejaculate of at least 72 hours. Seminal fluid was collected in to a pre warmed clean sterile plastic container (Olympic Plastics, Los Angeles, CA, Lot \# 10050, and USA). Samples were protected from extreme temperatures, not less than $22{ }^{\circ} \mathrm{C}$ and not more than $45{ }^{\circ} \mathrm{C}$ from the time of collection to the time of examination. Prior to examination samples were allowed to liquefy in an incubator at $37^{\circ} \mathrm{C}$ and semen analysis was done according to World Health Organizations stipulated guidelines ${ }^{16}$.

\section{Semen Analysis}

\section{Assessment of sperm count and concentration}

Thoroughly mixed Semen specimen was sampled with a standard white blood cell pipette (1:20 dilution, using sodium bicarbonate and phenol solution. $20 \mu \mathrm{l}$ of well shaken diluted specimen was transferred in to an improved Neubauer hemocytometer. Specimen was allowed 
to stay for 10 minutes and spermatozoa were counted using four chambers of hemocytometer. Average of the count was used for result analysis. The concentration of sperm was calculated by multiplying the above number with the dilution factor.

\section{Assessment of sperm motility}

Approximately $10 \mu \mathrm{l}$ of thoroughly mixed sample was spread with a bacteriological loop on a clean glass slide already kept at $37{ }^{\circ} \mathrm{C}$ in an incubator. Sample was covered with a standard cover slip to make a wet smear. The preparation was immediately examined under the microscope at the magnification of $x 40$. Whole procedure was repeated for three times and the average value was considered as final result.

\section{Measurement of semen volume}

The sample volume was measured with a disposable $5 \mathrm{ml}$ calibrated graduated cylinder to the nearest tenth of the millimeter.

\section{Assessment of sperm morphology}

Semen smear was made using $20 \mu \mathrm{l}$ of thoroughly mixed liquefied semen sample using sterilize glass slide. Smear was air dried and fixed with $10 \%$ formalin for one minute, rinsed in distilled water and stained for two minutes in Meyer's hematoxylin. Smear was allowed to air dry. Percent normal and abnormal morphology was determined from the rating of 200 spermatozoa using x100 objective.

\section{Statistical analysis}

Comparisons between mild, moderate and heavy smokers were performed by Student $t$ tests using SPSS program 17.0 (SPSS Institute, Inc.; Chicago, IL, USA) software. All results were tabulated as mean \pm standard deviation. A $p$ value $<0.05$ was considered as statistically significant.

\section{RESULTS AND DISCUSSION}

Data for the measurement of total sperm output and sperm concentration in smoker groups (100 each) in comparison with 100 age matched non smoker control semen specimens are presented in figures- 1 and 2 respectively. A consistent decrease in the level of total sperm output and sperm concentration in the smoker groups was observed, being significant in moderate smokers $(\mathrm{p}<0.005)$, and highly significant in heavy smoker group $(\mathrm{p}<0.0005)$. However this difference was found to be non significant in mild smoker group when compared with non smoker controls. 


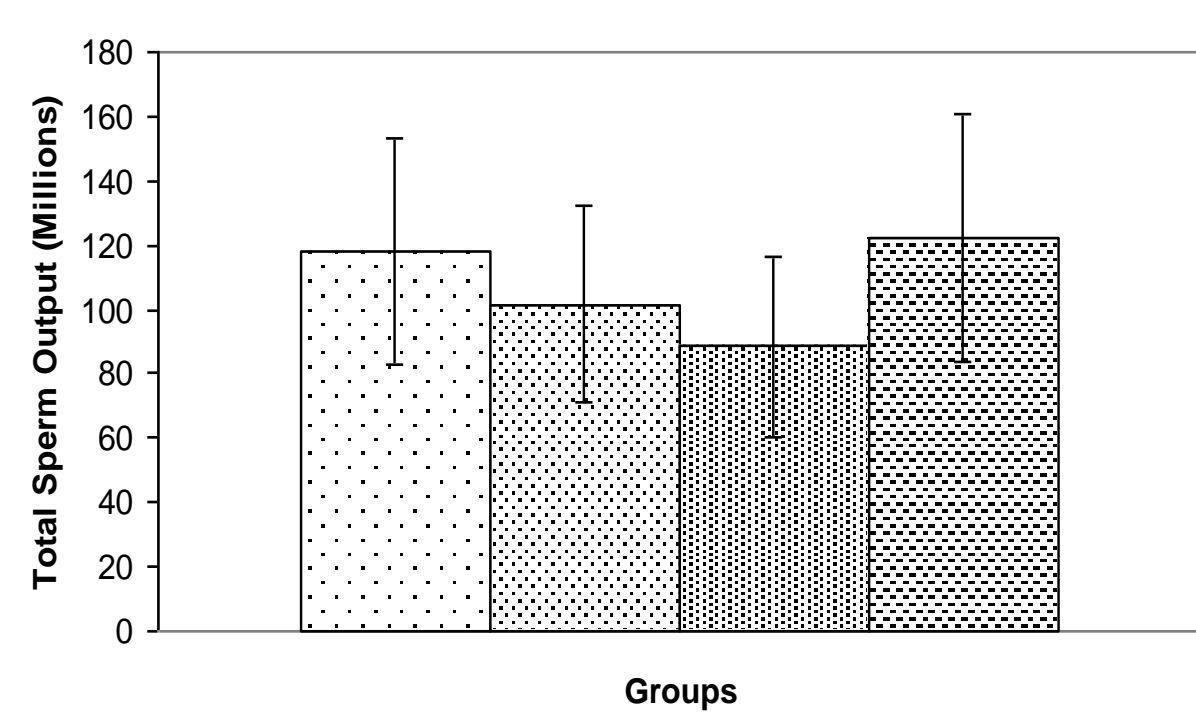

$\square$ Mild Smokers ๑ Moderate Smokers 国 Heavy Smokes ⿶. Non Smokers (Cotrol)

Figure 1: Measurement of sperm output (Millions) in mild, moderate, heavy cigarette smokers compared with the age matched non smokers control group in Saudi young men. Values are Mean \pm SD, $(n=100)$.

Note: $\mathbf{n}=$ Total number of subjects examined.

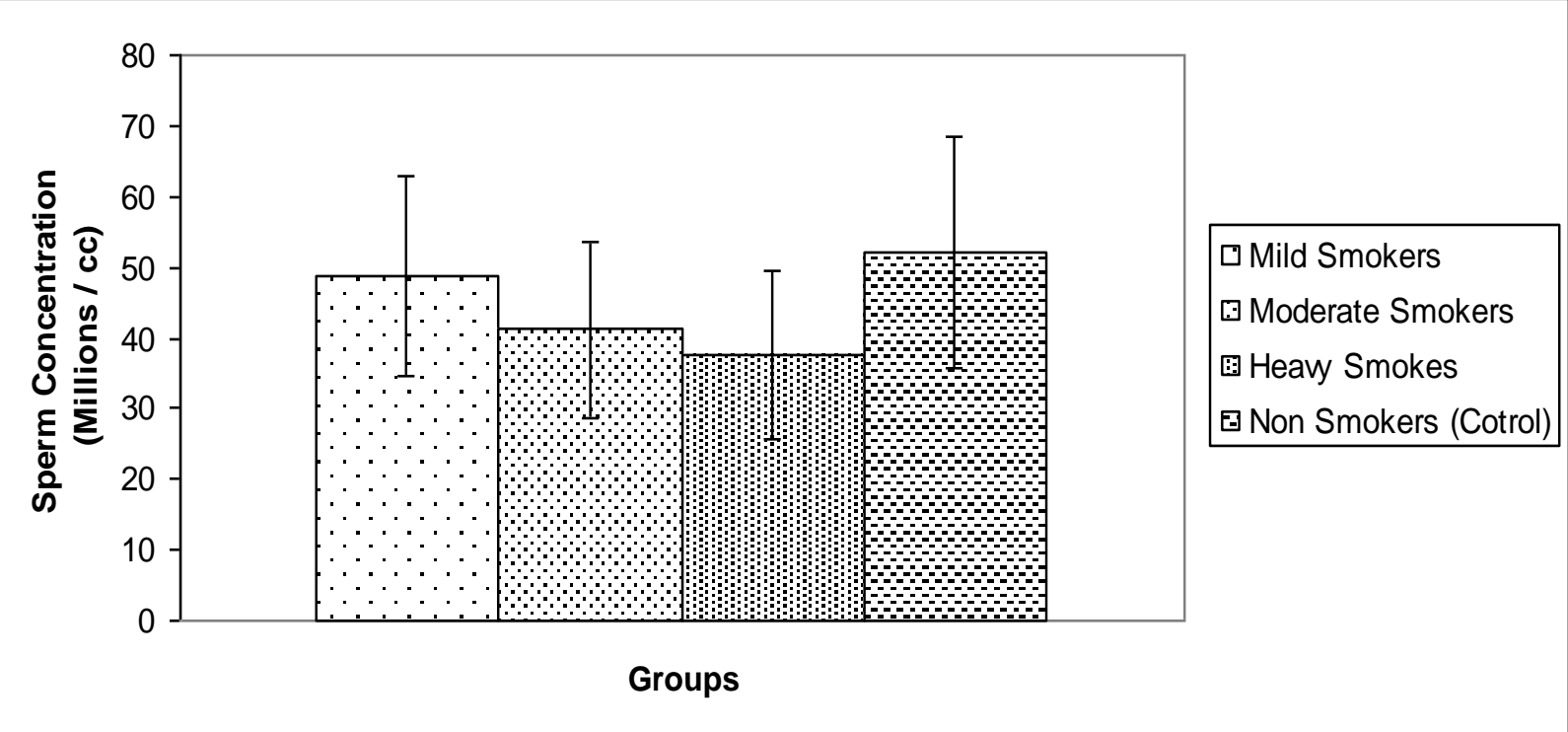

Figure 2: Measurement of sperm concentration (Millions / cc) in mild, moderate, heavy cigarette smokers compared with the age matched nonsmokers control group in Saudi young men. Values are Mean $\pm S D,(n=100)$.

Note: $\mathbf{n}=$ Total number of subjects examined.

The estimated values of percent sperm motility of the smoker groups and their age matched nonsmoker controls are presented in figure-3. A consistently decreased level of percentage motility of sperms was noted in almost all the semen specimen of the smoker groups. The values of the sperm motility were found to be significant $(\mathrm{p}<0.005)$ and highly significant $(\mathrm{p}<0.0005)$ in moderate and heavy smokers respectively than their respective controls. 
However this difference was found to be non significant in mild smoker group when compared with non smoker controls.

The values of semen volume were estimated in all types of smoker groups and their age matched nonsmoker control subjects and the results are enlisted in figure-4. In all the experiments on smoker groups the value of semen volumes were found to be higher $(p<0.005)$ and significantly higher $(\mathrm{p}<0.0005)$ in moderate and heavy smokers respectively from the specimens of their respective age matched control subjects, however a non-significant difference was observed between the values of mild smokers and their respective control subjects.

A comparison of the measured values of percentage sperm morphology (oval) and the quality of sperm motility by controls and all type of smoker groups is presented in figures-5 \& 6 respectively. A non-significant difference was observed in the measured values in mild smoker groups when compared with their age matched respective control groups. However both the values of percentage sperm morphology and the quality of sperm motility were found to be statistically significant $(\mathrm{p}<0.005)$ and highly significant $(\mathrm{p}<0.0005)$ in moderate and heavy smoker groups.

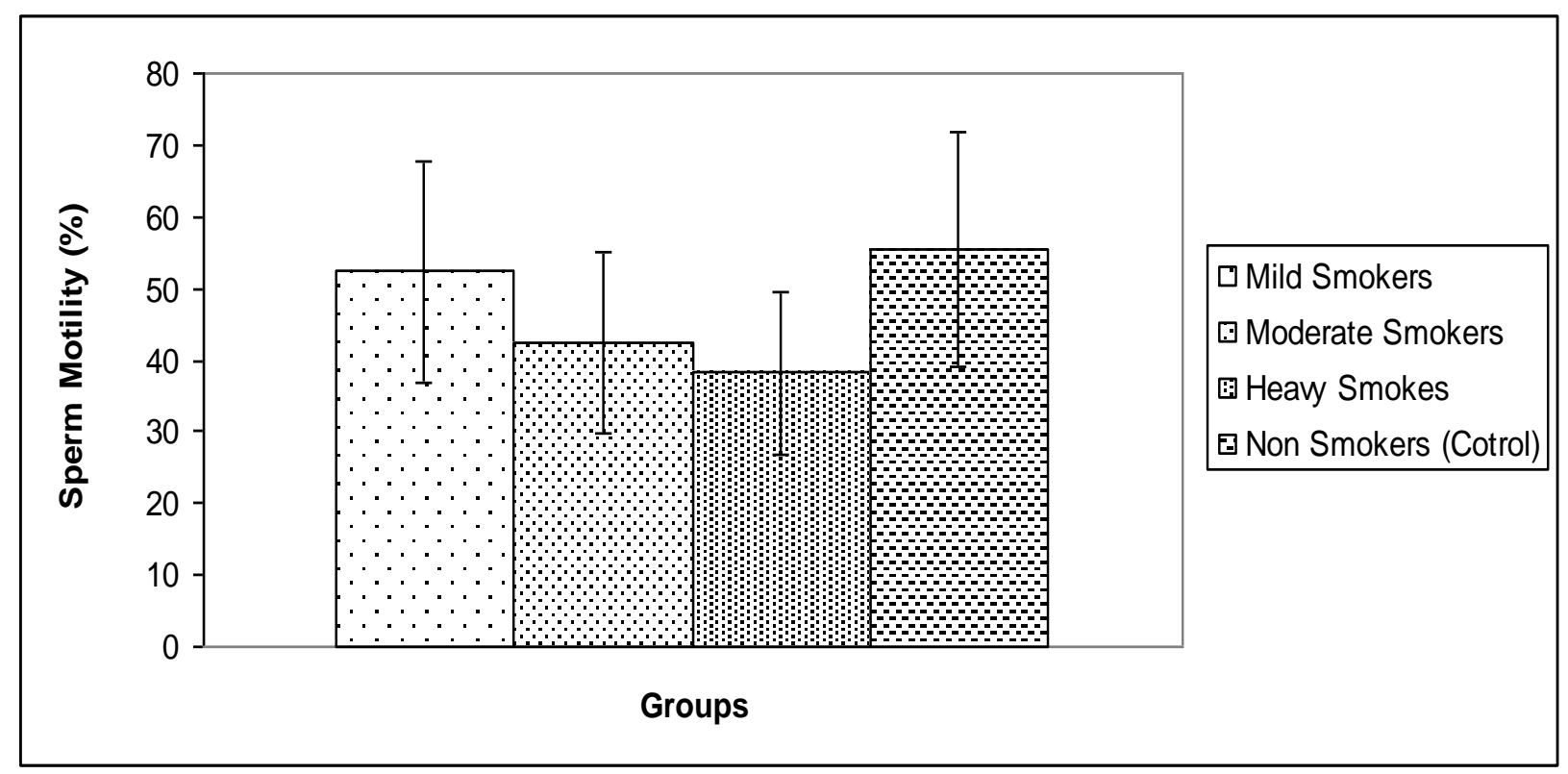

Figure 3: Measurement of sperm motility (\%) in mild, moderate, heavy cigarette smokers compared with the age matched non smokers control group in Saudi young men. Values are Mean $\pm \mathrm{SD},(\mathrm{n}=100)$.

Note $: \mathbf{n}=$ Total number of subjects examined. 


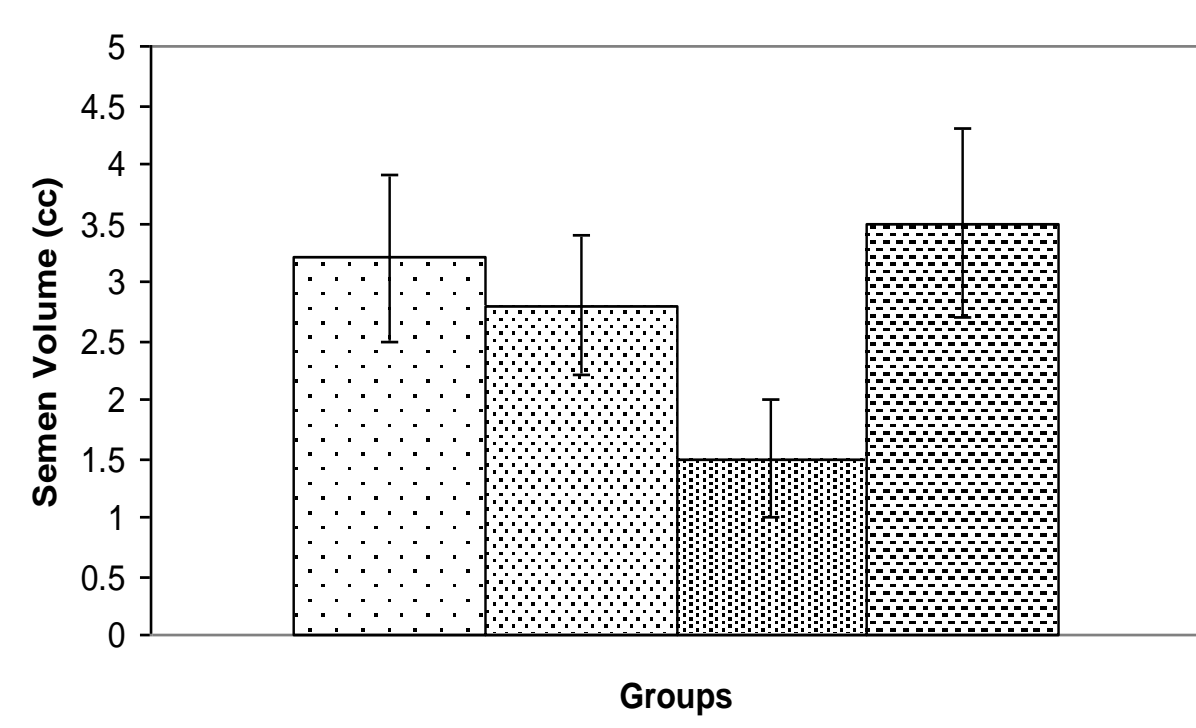

c Mild Smokers

$\checkmark$ Moderate Smokers

回 Heavy Smokes

⿴囗大 Non Smokers (Cotrol)

Figure 4: Measurement of semen volume (cc) in mild, moderate, heavy cigarette smokers compared with the age matched non smokers control group in Saudi young men. Values are Mean $\pm S D,(n=100)$.

Note: $\mathbf{n}=$ Total number of subjects examined.

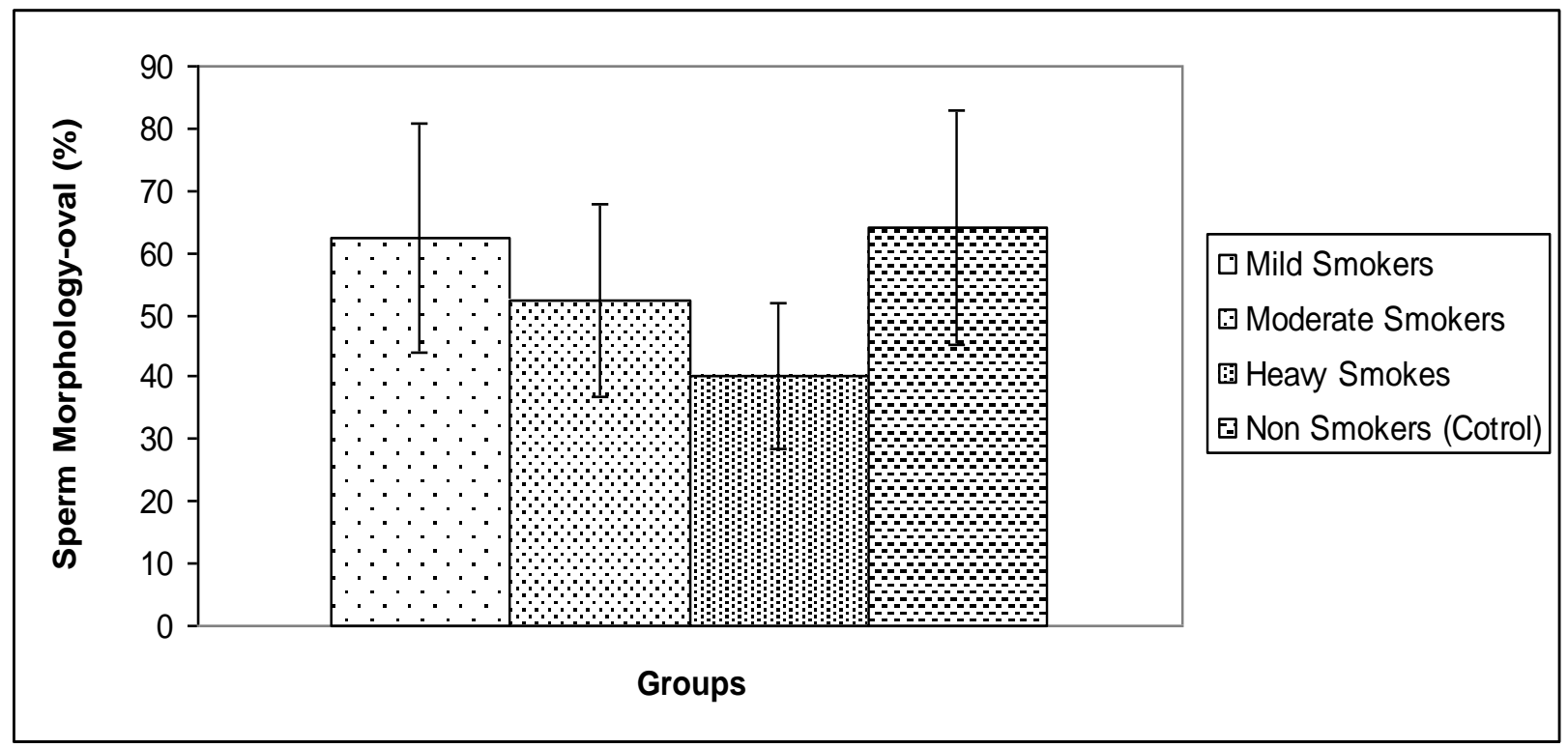

Figure 5: Measurement of sperm morphology-oval (\%) in mild, moderate, heavy cigarette smokers compared with the age matched nonsmokers control group in Saudi young men. Values are Mean $\pm S D,(n=100)$.

Note: $\mathbf{n}=$ Total number of subjects examined. 


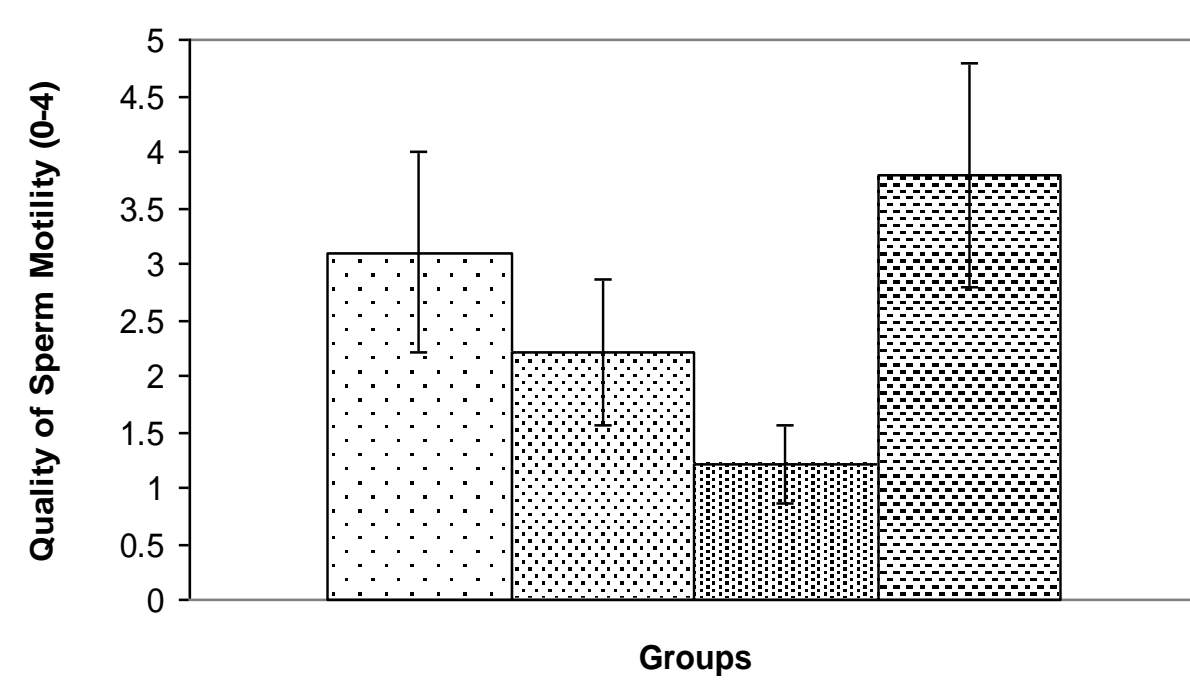

$\square$ Mild Smokers $\checkmark$ Moderate Smokers 国 Heavy Smokes a Non Smokers (Cotrol)

Figure 6: Measurement of quality of sperm motility (0-4) in mild, moderate, heavy cigarette smokers compared with the age matched nonsmokers control group in Saudi young men. Values are Mean $\pm \mathrm{SD},(n=100)$.

Note: $\mathbf{n}=$ Total number of subjects examined.

\section{DISCUSSION}

Findings from this study underscore the fact that cigarette smoking has adverse reproductive outcome on semen quality. The results in this study showed that total sperm count and concentration, percentage motility, semen volume, morphology and quality of sperm motility were all lower in smokers compared with non-smokers (Figures 1-6). The observed reductions in semen volume in smokers compared with non-smokers have been reported by others. ${ }^{17-18}$. Results from this study further showed that the reduction in semen volume in smokers was associated to the number of sticks smoked per day. This could be the result of the presence of nicotine in cigarette, which affects the functioning of accessory sex glands (seminal vesicle, prostate and urethral glands), that control semen volume through their secretions. ${ }^{19}$ In this study, sperm motility was significantly lower in smokers compared with non-smokers. This finding was supported by previous studies ${ }^{20,21,22}$. This is the result of the mutagenic effects of aromatic hydrocarbons ${ }^{23}$ and the toxic effects of nicotine ${ }^{24}$ that can disrupt the testicular microcirculation, thereby reducing the number of red blood cells reaching the cells of the testes to supply oxygen for respiration. Carbon monoxide found in cigarette smoke is also known to reduce availability of oxygenated hemoglobin, leading to a reduced supply of oxygen to the sperm cell ${ }^{25}$ which results in a decreased utilization of oxygen by the mitochondria of the sperm cells ${ }^{26}$ thereby reducing the motility of the sperms, hence sluggish sperms. The sperm tail contains lots of mitochondria; therefore, ultra-structural damage in the tail region as a result of smoking can impair mitochondrial function. 
On sperm morphology, the results of this study showed that smokers had significantly lower normal sperm morphology compared with non-smokers and the frequency of abnormal morphology increased as the number of tobacco sticks smoked per day increased; putting smokers at a higher risk of developing teratozoospermia. This study was in agreement with others ${ }^{27,28}$ who reported that cigarette smoking increases the percentage of morphologically altered spermatozoa. This is as a result of the presence of toxic chemicals, mutagenic and carcinogenic compounds found in cigarette smoke, which adversely affect sperm morphology 29

Several studies have reported that the mutagenic components of cigarette smoke adversely affected rapidly dividing cells, including germ cells in the testis ${ }^{30}$ MacKenzie and Angeline ${ }^{31}$ demonstrated that polycyclic aromatic hydrocarbons and nicotine present in cigarette smoke can cause atrophy of seminiferous tubules, testis and reduce or block spermatogenesis. In this study, the significantly lower sperm concentration, total sperm concentration, in smokers compared with non-smokers were the results of mutagenic compounds present in cigarette. Total sperm count which is a function of semen volume and sperm count was also significantly lower in smokers than in non-smokers. The study further revealed that smokers were at higher risk of developing oligospermia compared with non-smokers and that the effect was dosedependent. This corroborated with a prior study ${ }^{32}$. The presence of nicotine in cigarette impairs spermatogenesis that makes smokers to be at higher risk of developing reduced total sperm count as compared with non-smokers ${ }^{33}$.

Semen abnormalities (oligospermia, asthenozoospermia and teratozoospermia) were present in this study (data not shown). The results showed that semen abnormalities were more prevalent among heavy smokers compared to moderate and mild smokers. These abnormalities were dose-dependent and in agreement with prior studies ${ }^{34}$.

\section{CONCLUSION}

This study showed that moderate to heavy smoking significantly reduced the seminal parameters including sperm output and concentration, sperm morphology, semen volume as well as sperm motility and forward progression. This reduction in semen quality was found to be associated in a dose-dependent manner. We conclude that cigarette smoking has a significant adverse reproductive outcome in younger aged Saudi men.

\section{FOOT NOTE}

This research is a part of on going vertical module research project, Department of Physiology, College of Medicine, Umm-Al- Qura University, Makkah, Saudi Arabia.

\section{REFERENCES}

1. Gowing LR, Ali RL, Allsop S, Marsden J, Turf EE, West R, et al. Global statistics on 
addictive behaviors: 2014 status report. Addiction. 2015; 110(6): 904-19.

2. Bassiony MM. Smoking in Saudi Arabia. Saudi medical journal. 2009; 30(7): 876-81.

3. Leone A. Toxics of Tobacco Smoke and Cardiovascular System: From Functional to Cellular Damage. Current pharmaceutical design. 2015; 21(30): 4370-9.

4. Onor IO, Stirling DL, Williams SR, Bediako D, Borghol A, Harris MB, et al. Clinical Effects of Cigarette Smoking: Epidemiologic Impact and Review of Pharmacotherapy Options. International journal of environmental research and public health. 2017; 14(10): 1147.

5. CDC. Health Effects of Cigarette Smoking 2017 May 17 [cited 2019 25/2/2019]. Available

from:https://www.cdc.gov/tobacco/data_statistics/fact_sheets/health_effects/effects_ci g_smoking/index.htm.

6. Abate M, Vanni D, Pantalone A, Salini V. Cigarette smoking and musculoskeletal disorders. Muscles, ligaments and tendons journal. 2013; 3(2): 63-9.

7. Pomerleau OF. Nicotine and the central nervous system: bio behavioral effects of cigarette smoking. The American journal of medicine. 1992; 93(1A): 2S-7S.

8. Sharma R, Harlev A, Agarwal A, Esteves SC. Cigarette Smoking and Semen Quality: A New Meta-Analysis Examining the Effect of the 2010 World Health Organization Laboratory Methods for the Examination of Human Semen. European urology. 2016; 70(4): 635-45.

9. Mostafa RM, Nasrallah YS, Hassan MM, Farrag AF, Majzoub A, Agarwal A. The effect of cigarette smoking on human seminal parameters, sperm chromatin structure and condensation. Andrologia. 2018; 50(3). 1110-16.

10. Al-Turki HA. Effect of smoking on reproductive hormones and semen parameters of infertile Saudi Arabians. Urology annals. 2015; 7(1): 63-6.

11. Ramlau-Hansen CH, Thulstrup AM, Aggerholm AS, Jensen MS, Toft G, Bonde JP. Is smoking a risk factor for decreased semen quality? A cross-sectional analysis. Human reproduction (Oxford, England). 2007; 22(1): 188-96.

12. Dai JB, Wang ZX, Qiao ZD. The hazardous effects of tobacco smoking on male fertility. Asian Journal of Andrology. 2015; 17(6): 954-60.

13. Kovac JR, Labbate C, Ramasamy R, Tang D, Lipshultz LI. Effects of cigarette smoking on erectile dysfunction. Andrologia. 2015; 47(10): 1087-92.

14. AlEnezi H, Isa AM, Abu-Rafea B, Madbouly K, Binsaleh S. Pattern of semen fluid abnormalities in male partners of infertile couples in Riyadh, Saudi Arabia. The Canadian journal of urology. 2014; 21(3): 7322-5. 
15. Al-Turki HA. A 5-year analysis of semen parameters in Saudi Arabian men attending infertility clinics. The Journal of international medical research. 2016; 44(3): 656-61.

16. WHO. Laboratory Manual for the Examination of Human Semen and Sperm-Cervical Mucus Interactions. WHO. 2010; 1-107.

17. Multigner L, Magistrini M, Ducot BSA. Environment and secular sperm trend. Stallion's semen quality during the last two decades. Rev Epidemiol Sante Publique. 2000;48: 72-78.

18. Bao HQ, Sun L, Yang XN, Ding J, Ma SY, Yang L, Xu XO. Impact of cigarette smoking on sperm quality and seminal plasma ROS in preconception males. Zhonghua Nan Ke Xue. 2019;25(1):41-45. Chinese.

19. Wang W, Yang X, Liang J, Liao M, Zhang H, Qin X, Mo L, Lv W, Mo Z. Cigarette smoking has a positive and independent effect on testosterone levels. Hormones. 2013;12: 567-577.

20. Olayaki LA, Edeoga EO, Jimoh OR, Ghazal OK, Jimoh AG, Biliaminu SA. Effect of cigarette smoking on urinary testosterone excretion in men. Biokemistri. 2008;20: 2932.

21. Sofikitis N, Miyagawa I, Dimitriadis D, Zavos P, Sikka S, Hellstrom W. Effects of smoking on testicular function, semen quality and sperm fertilizing capacity. $\mathbf{J}$ Urol. 1995;154: 1030-1034.

22. Zinaman MJ, Brown CC, Selevan SG, Clegg ED. Semen quality and human fertility: a prospective study with healthy couples. J Androl. 2000;21: 145-153.

23. Kier LD, Yamasaki E, Ames BN. Detection of mutagenic activity in cigarette smoke condensates. Proc Atl Acad Sci. 1974;71: 4159-4163.

24. Mattison DR. The effects of smoking on fertility from gametogenesis to implantation. Environ Res. 1982;28: 410-433.

25. Kaufman DW, Helmrich SP, Rosenberg L, Miettinen OS, Shapiro S. Nicotine and carbon monoxide content of cigarette smoke and the risk of myocardial infarction in young men. N Engl J Med. 1983;308: 409-413.

26. Chohan KR, Badawy SZA. Cigarette smoking impairs sperm bioenergetics. Int Braz J Urol. 2010;36: 60-65.

27. Evans HJ, Fletcher J, Torrance M, Hargreave TB. Sperm abnormalities and cigarette smoking. Lancet. 1981;1: 627-629.

28. Elshal MF, El-Sayed IH, Elsaied MA, El-Masry SA, Kumosani TA. Sperm head defects and disturbances in spermatozoal chromatin and DNA integrities in idiopathic infertile subjects: association with cigarette smoking. Clin Biochem. 2009;42: 589-594. 
29. Morrow JD, Frei B, Longmire AW, Gaziano JM, Lynch SM, Shyr Y, Strauss WE, Oates JA, Roberts LJ. Increase in circulating products of lipid peroxidation (F2-Isoprostanes) in smokers. N Engl J Med. 1995;332: 1198-1203.

30. Sorahan T, Prior P, Lancashire RJ, Faux SP, Hulten MA, Peck IM, Stewart AM. Childhood cancer and parental use of tobacco: deaths from 1971 to $1976 . \mathrm{Br} \mathrm{J}$ Cancer. 1997;76: 1525-1531.

31. MacKenzie KM, Angevine DM. Infertility in mice exposed in utero to benzo(a) pyrene. Biol Reprod. 1981;24: 183-191.

32. Chia SE, Ong CN, Lee ST, Tsakok FH. Study of the effects of occupation and industry on sperm quality. Ann Acad Med Singapore. 1994;23: 645-649.

33. Yardimci S, Atan A, Delibasi T, Sunguroglu K, Guven MC. Long-term effects of cigarette-smoke exposure on plasma testosterone, luteinizing hormone and folliclestimulating hormone levels in male rats. Br J Urol. 1997;79: 66-69.

34. Carlsen E, Giwercman A, Keiding N, Skakkebaek NE. Evidence for decreasing quality of semen during past 50 years. BMJ. 1992;305: 609-613.

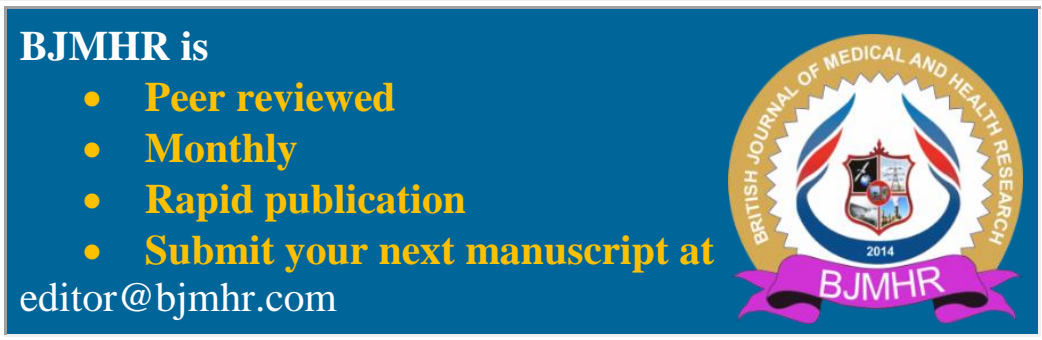

